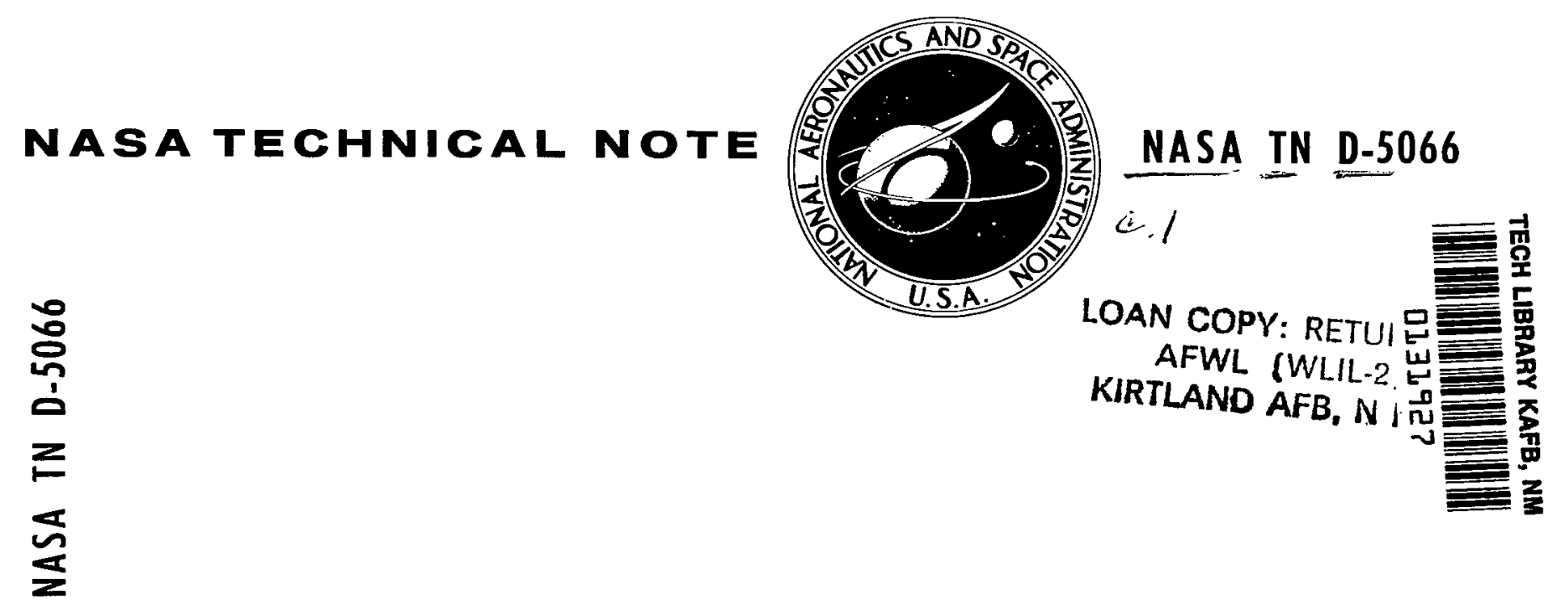

\title{
HARTREE-FOCK CALCULATIONS WITH WOOD-SAXON BASIS FUNCTIONS
}

by William F. Ford and Richard C. Braley

Lewis Research Center

Cleveland, Obio

NATIONAL AERONAUTICS AND SPACE ADMINISTRATION • WASHINGTON, D. C. - FEBRUARY 1969 
By William F. Ford and Richard C. Braley

Lewis Research Center

Cleveland, Ohio

NATIONAL AERONAUTICS AND SPACE ADMINISTRATION

For sale by the Clearinghouse for Federal Scientific and Technical Information

Springfield, Virginia 22151 - CFSTI price $\$ 3.00$ 


\section{ABSTRACT}

The Hartree-Fock method is used to study the even-even $\mathrm{N} Z$ nuclei in the $2 \mathrm{~s}-1 \mathrm{~d}$ shell. Basis functions with correct asymptotic behavior are generated by use of a WoodSaxon well. The results are compared with calculations using the conventional harmonic oscillator basis. It is found that most of the Wood-Saxon results may be obtained with a harmonic oscillator basis if the oscillator parameter is carefully chosen. 


\title{
HARTREE-FOCK CALCULATIONS WITH WOOD-SAXON BASIS FUNCTIONS
}

\author{
by William F. Ford and Richard C. Braley \\ Lewis Research Center
}

\author{
SUMMARY
}

In order to deter mine the sensitivity of various nuclear properties to the asymptotic part of the nuclear wave function, calculations have been made using both the conventional harmonic oscillator single-particle functions and the more realistic Wood-Saxon functions. Hartree-Fock theory was used to obtain nuclear wave functions for the five even-even $\mathrm{N}=\mathrm{Z}$ nuclei in the $2 \mathrm{~s}-1 \mathrm{~d}$ shell. Intrinsic nuclear energies, radii, and quadrupole moments were calculated, as well as energy gaps and single-particle densities. Considerable differences between harmonic oscillator and Wood-Saxon results were found when the usual value $\left(\nu=0.35 \mathrm{fm}^{-2}\right)$ for the cscillator parameter was used; however, close agreement could be obtained in most of the properties studied by using a different value $\left(\nu=0.27 \mathrm{fm}^{-2}\right)$.

\section{INTRODUCTION}

In recent years the Hartree-Fock (HF) method has received considerable attention in studies of the energy levels of deformed nuclei (ref. 1). This method is essentially a variational procedure, based on minimization of the energy of a many-particle system. While such a procedure may provide a sensitive test of the wave function in the nuclear interior, it is expected that the shape of the wave function beyond the nuclear surface will not affect nuclear energies significantly. For this reason, HF calculations up until now have made use of single-particle harmonic oscillator basis functions, in spite of their obviously incorrect asymptotic behavior.

There are, however, many quantities of interest which are expected to be much more sensitive than the total energy to the asymptotic part of the wave function. Electromagnetic transition rates, multipole moments, and form factors for elastic and inelastic scattering are examples which come readily to mind. It does not seem likely that very accurate calculations of such quantities can be performed using HF wave functions with a harmonic oscillator basis. Thus, a HF calculation using the basis functions of the more 
realistic Wood-Saxon potential is of interest both for the energy spectrum it yields and for the effect it shows of the long-range part of the wave function on other nuclear properties.

In this report are presented the results of a considerably restricted version of such a program. The HF variational calculation is carried out for five nuclei in the $2 \mathrm{~s}-1 \mathrm{~d}$ shell by using both Wood-Saxon (WS) and harmonic oscillator (HO) basis functions. A comparison is made of such properties as orbital energies, energy gap, and total (HF) energy. In addition, nuclear densities, radii, and intrinsic quadrupole moments are calculated and compared.

\section{SYMBOLS}

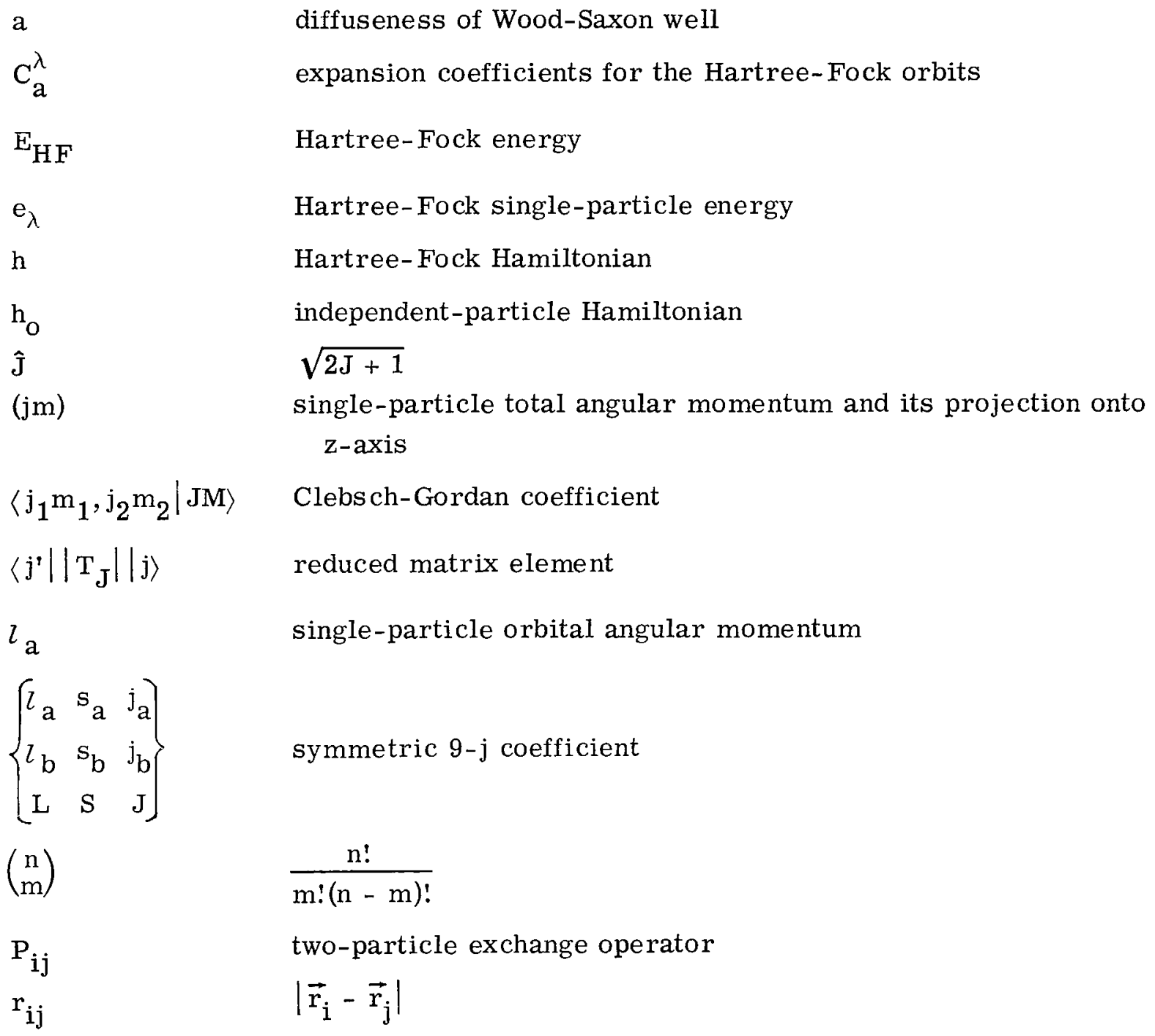


$\left(\mathrm{SM}_{\mathrm{S}}\right)$

$\mathrm{U}\left(\mathrm{j}_{1} \mathrm{j}_{2} \mathrm{j}_{4} \mathrm{j}_{3} ; \mathrm{J} 12^{\mathrm{J}}\right)$

$u_{a}(i)$

$\mathrm{u}_{\mathrm{a}}\left(\mathrm{r}_{\mathrm{i}}\right)$

$\mathrm{V}(\mathrm{ij})$

$\mathrm{V}_{\mathrm{o}}$

$\mathrm{v}(\mathrm{i})$

$\mathrm{W}\left(\mathrm{j}_{1} \mathrm{j}_{2} \mathrm{j}_{4} \mathrm{j}^{\mathrm{J}}{ }_{12}^{\mathrm{J}}\right)$

$\mathrm{Y}_{\mathrm{L}}^{\mathrm{m}}(\mathrm{i})$

$\mathrm{Y}_{l \mathrm{sj}}^{\mathrm{m}}(\mathrm{i})$

$\Delta$

$\mu$

$\nu$

$\rho(\mathrm{r})$

$\rho_{\mathrm{v}}(\mathrm{r})$

$\vec{\sigma}(\mathrm{i})$

$\tau_{\mathbf{a}}$

$\int \mathrm{d} \tau_{\mathbf{j}}$

$\Phi$

$\varphi_{\lambda}(\mathrm{i})$

$x_{\mathbf{S M}_{\mathrm{S}}}$

$x_{S}^{m}(i)$

$x_{1 / 2}^{\tau}(\mathrm{i})$ total spin angular momentum and projection onto $\mathrm{z}$-axis

U-coefficient of Jahn (see ref. 9); defined in terms of Racah coefficient as $\left[\left(2 \mathrm{~J}_{12}+1\right)(2 \mathrm{~J}+1)\right]^{1 / 2} \mathrm{~W}\left(\mathrm{j}_{1} \mathrm{j}_{2} \mathrm{j}_{4} \mathrm{j}_{3} ; \mathrm{J}_{12} \mathrm{~J}\right)$

$\mathrm{u}_{\mathrm{a}}\left(\mathrm{r}_{\mathrm{i}}\right) \mathrm{Y}_{l \mathrm{a}}^{\mathrm{m} / 2 \mathrm{j}_{\mathrm{a}}} \mathrm{m}_{\mathrm{i}) \mathrm{x}_{1 / 2}^{\tau}}^{(\mathrm{i})}$

radial part of basis function

residual two-body force

strength of residual two-body force and/or Wood-Saxon well

nonlocal part of the Hartree-Fock Hamiltonian

Racah coefficient

spherical harmonic

$$
\sum_{\mathrm{m}_{1} \mathrm{~m}_{2}}\left\langle\imath \mathrm{m}_{1}, \mathrm{sm}_{2} \mid \mathrm{jm}\right\rangle \mathrm{Y}_{l}^{\mathrm{m}_{1}}{ }_{(\mathrm{i}) \mathrm{x}_{\mathrm{s}}{ }^{\mathrm{m}_{2}}(\mathrm{i})}
$$

energy gap between occupied and unoccupied orbits

nucleon-nucleon force range

Harmonic os cillator parameter

single-particle density function which includes core effects

single-particle density function for valence particles only

Pauli spin operator for particle i

$z$-projection of single-particle isotopic spin

integral over all coordinates of $j^{\text {th }}$ particle

determinantal wave function for A-particle system

Hartree-Fock orbital function of $i^{\text {th }}$ particle

total spin wave function for two-particle system

spin wave function for $i^{\text {th }}$ particle

isospin function for $i^{\text {th }}$ particle 


\section{THEORY}

In the HF method, the nuclear wave function is approximated by the Slater deter minant

$$
\Phi=(\mathrm{A} !)^{-1 / 2} \operatorname{det}\left\{\varphi_{\lambda}(\mathrm{i})\right\}
$$

whose orbital functions $\varphi_{\lambda}$ (i) are determined by minimizing the expectation value of the nuclear Hamiltonian. This variational problem leads to the eigenvalue equation

$$
\mathrm{h} \varphi_{\lambda}=\left(\mathrm{h}_{\mathrm{o}}+\mathrm{v}\right) \varphi_{\lambda}=\epsilon_{\lambda} \varphi_{\lambda}
$$

where

$$
\mathrm{v}(\mathrm{i})=\frac{1}{2} \sum_{\mu} \int \mathrm{d} \tau_{\mathrm{j}} \varphi_{\mu}^{*}(\mathrm{j}) \mathrm{V}(\mathrm{ij})\left(1-\mathrm{P}_{\mathrm{ij}}\right) \varphi_{\mu}^{(\mathrm{j})}
$$

The operator $h_{0}$ is usually taken to be the Familtonian for a single nucleon moving in the average nuclear field, and $\mathrm{V}$ represents the residual two-body force. The presence of the exchange operator $P_{i j}$ is a natural consequence of the antisymmetry of the determinant. The summation in equation (3) is taken over all the orbits which are to be varied.

Since equations (2) and (3) are too difficult for a direct solution, approximation methods are required. Usually one begins by selecting a suitable set of basis functions and then making the expansion

$$
\varphi_{\lambda}^{(i)}=\sum_{\mathbf{a}} \mathrm{C}_{\mathbf{a}^{\mathrm{u}} \mathrm{u}^{(\mathrm{i})}}^{\lambda}
$$

The problem then reduces to diagonalizing $h$ in the space spanned by the basis functions $u_{\mathrm{a}}$. In practice, this is accomplished in an approximate way by first truncating the space, then guessing at an initial set $\mathrm{C}_{\mathrm{a}}^{\lambda}$, and finally iterating until two successive diagonalizations yield the same set $C_{a}^{\lambda}$. (Often "a" will be written for the set $j_{a} m_{a}$, the set $j_{a}$, or even the set $n_{a} l_{a} j_{a}$ when no confusion will result.)

In order to carry out this procedure, one needs matrix elements of $h$. It is generally assumed that $h_{0}$ is diagonal with eigenvalues deduced from experimental spectra. The matrix elements of $\mathrm{v}$ may be expressed (ref. 1) in terms of the coupled two-body 
matrix elements of $\mathrm{V}$ :

$$
\begin{aligned}
& \langle a|v| c\rangle=\frac{1}{2} \sum_{\mu} \sum_{b d}\left(c_{b}^{\mu} *_{c}^{\mu}\right) \sum_{J T}\left\langle j_{a} m_{a}, j_{b} m_{b} \mid J M\right\rangle\left\langle j_{c} m_{c}, j_{d} m_{d} \mid J M\right\rangle \\
& \times\left\langle\frac{1}{2} \tau_{\mathrm{a}}, \frac{1}{2} \tau_{\mathrm{b}} \mid \mathrm{T} \mathrm{M}_{\mathrm{T}}\right\rangle\left\langle\frac{1}{2} \tau_{\mathrm{c}}, \frac{1}{2} \tau_{\mathrm{d}} \mid \mathrm{TM} \mathrm{T}\right\rangle\langle\mathrm{ab}|\mathrm{V}| \tilde{\mathrm{cd}}\rangle_{\mathrm{T}}
\end{aligned}
$$

(The tilde indicates that the product function $u_{c}(i) u_{d}(j)$ has been antisymmetrized.) The two-body matrix elements $\langle a b|V| \widetilde{c d}\rangle_{J T}$ are of course independent of the orbital functions, and they are therefore ideally suited for use as input in a general program designed to solve equation (2).

Calculation of the two-body matrix elements presents some problems which stem from the fact that $V(i j)$ is a function of the separation between nucleons $i$ and $j$. If HO functions are used, one can overcome the difficulty by transforming to center-ofmass and relative coordinates, and the resulting integrals can be expressed in terms of Moshinsky brackets (ref. 2). In the general case, however, such a transformation is not possible, and the most promising approach seems to be an expansion of $\mathrm{V}(\mathrm{ij})$.

For the moment the isotopic spin dependence is ignored. The coupled matrix element may then be written

$$
\langle\mathrm{ab}|\mathrm{V}| \tilde{\mathrm{cd}}\rangle_{\mathrm{J}}=\left\langle\varphi_{\mathrm{JM}}^{\mathrm{ab}}(12)|\mathrm{V}(12)| \varphi_{\mathrm{JM}}^{\mathrm{cd}}(12)-\varphi_{\mathrm{JM}}^{\mathrm{cd}}(21)\right\rangle
$$

where

$$
\varphi_{J M}^{a b}(12)=\sum_{m_{a} m_{b}}\left\langle j_{a} m_{a}, j_{b} m_{b} \mid J M\right\rangle u_{a}(1) u_{b}(2)=(-1){ }_{a}^{j_{a} j_{b}-J} \varphi_{J M}^{b a}(21)
$$

After switching from $\mathrm{j}-\mathrm{j}$ to $\mathrm{L}-\mathrm{S}$ coupling (ref. 3) by means of

$$
\varphi_{\mathrm{JM}}^{\mathrm{ab}}=\sum_{\mathbf{M}_{\mathrm{L}} \mathrm{M}_{\mathrm{S}}}\left\langle\mathrm{LM}_{\mathrm{L}}, \mathrm{SM}_{\mathrm{S}} \mid J \mathrm{M}\right\rangle \varphi_{\mathrm{LM}_{\mathrm{L}}}^{\mathrm{ab}} \chi_{\mathrm{SM}_{\mathrm{S}}}
$$

we obtain 


$$
\begin{aligned}
& \left\langle\varphi_{J_{M}}^{\mathrm{ab}}(12)|\mathrm{V}(12)| \varphi_{\mathrm{JM}^{(i j)}}^{\mathrm{cd}}\right\rangle=\sum_{\mathrm{LS}} \mathrm{Q}_{\mathrm{LSJ}}^{\mathrm{ab}} \mathrm{Q}_{\mathrm{LSJ}}^{\mathrm{cd}} \\
& \times\left\langle\varphi_{\mathrm{LM}_{\mathrm{L}}}^{\mathrm{ab}}(12) \mathrm{x}_{\mathrm{SM}_{\mathrm{S}}}{ }^{(12)}|\mathrm{V}(12)| \varphi_{\mathrm{LM}_{\mathrm{L}}}^{\mathrm{cd}}(\mathrm{ijj}) \mathrm{x}_{\mathrm{SM}_{\mathrm{S}}}^{(\mathrm{ij})}\right\rangle
\end{aligned}
$$

where $M_{L}+M_{S}=M$ and

$$
Q_{L S J}^{a b} \equiv \hat{L} \hat{S}_{\mathbf{j}_{\mathrm{a}}} \hat{j}_{\mathrm{b}}\left\{\begin{array}{ccc}
l_{\mathrm{a}} & 1 / 2 & \mathrm{j}_{\mathrm{a}} \\
l_{\mathrm{b}} & 1 / 2 & \mathrm{j}_{\mathrm{b}} \\
\mathrm{L} & \mathrm{S} & \mathrm{J}
\end{array}\right\}
$$

In this derivation $\mathrm{V}$ is assumed invariant under space and spin rotations separately. Usually a spin dependence of the form

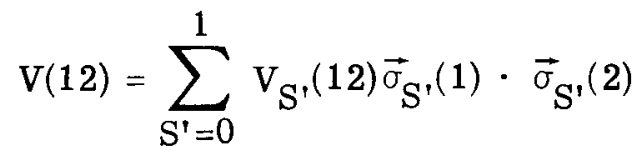

is also assumed where $\vec{\sigma}_{0}$ is the unit operator in spin space and $\vec{\sigma}_{1}$ is the ordinary Pauli spin operator. Then, since $X_{S}(12)=(-1)^{1+S_{X}} X_{S}(21)$,

$$
\begin{aligned}
\langle a b|V| \tilde{c d}\rangle_{J}=\sum_{L S} Q_{L S J^{2}}^{a b} Q_{L S J}^{c d} \sum_{S^{\prime}} & A_{S^{\prime}} \\
& \times\left\langle\varphi_{L_{M}}^{a b}(12)\left|V_{S^{\prime}}(12)\right| \varphi_{L_{M}}^{c d}(12)+(-1)^{S} \varphi_{L M}^{c d}(21)\right\rangle
\end{aligned}
$$

where

$$
\begin{aligned}
A_{\mathrm{SS}^{\prime}} & \equiv\left\langle\mathrm{S} \| \vec{\sigma}_{\mathrm{S}^{\prime}}(1) \cdot \vec{\sigma}_{\mathrm{S}^{\prime}}(2)|| \mathrm{S}\right\rangle \\
& =2\left(2 \mathrm{~S}^{\prime}+1\right)(-1)^{\mathrm{S}-1} \mathrm{~W}\left(\frac{1}{2} \frac{1}{2} \frac{1}{2} \frac{1}{2} \mid \mathrm{S}^{\prime} \mathrm{S}\right)=1-4 \delta_{\mathrm{S} 0}{ }^{\delta} \mathrm{S}^{\prime} 1
\end{aligned}
$$

Next the spherical harmonics in $\varphi_{\mathrm{LM}}^{\mathrm{ab}}$ and $\varphi_{\mathrm{LM}}^{\mathrm{cd}}$ are decoupled and then recoupled according to 


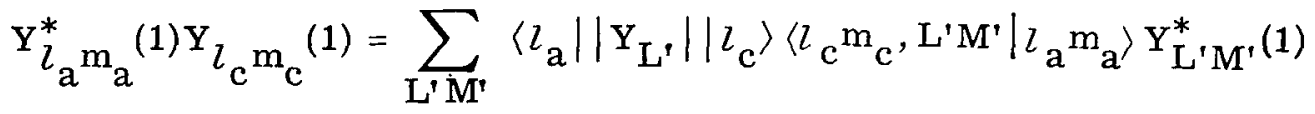

$$
\begin{aligned}
& \mathrm{Y}_{l_{\mathrm{b}} \mathrm{m}_{\mathrm{b}}}^{*}(2) \mathrm{Y}_{\iota_{\mathrm{d}} \mathrm{m}_{\mathrm{d}}}(2)=\sum_{\mathrm{L}^{\prime \prime} \mathrm{M}^{\prime \prime}}\left\langle\iota_{\mathrm{d}}|| \mathrm{Y}_{\mathrm{L}^{\prime \prime}}|| \iota_{\mathrm{b}}\right\rangle\left\langle\iota_{\mathrm{b}} \mathrm{m}_{\mathrm{b}}, \mathrm{L}^{\prime \prime} \mathrm{M}^{\prime \prime} \mid \iota_{\mathrm{d}} \mathrm{m}_{\mathrm{d}}\right\rangle \mathrm{Y}_{\mathrm{L}^{\prime \prime} \mathrm{M}^{\prime \prime}}(2)
\end{aligned}
$$

Now, after a little more Racah algebra, the coupled matrix element may be written

$$
\begin{aligned}
\langle a b|V| \tilde{c d}\rangle_{J}=\sum_{L S} Q_{L S J^{\prime}}^{a b} Q_{L S J}^{c d} \sum_{L^{\prime} S^{\prime}} A_{S S^{\prime}}\left[B_{L L^{\prime}}^{a c, d b} F_{L^{\prime} S^{\prime}}^{a c, d b}\right. & \\
& \left.+(-1)^{L+S+l} c^{+l} d_{B_{L L^{\prime}}}^{a d, c b} F_{L^{\prime} S^{\prime}}^{a d, c b}\right]
\end{aligned}
$$

where

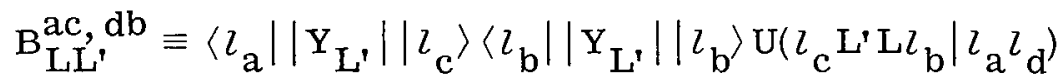

$$
\begin{aligned}
& \mathrm{F}_{\mathrm{LS}}^{\mathrm{ac}, \mathrm{db}}=\left\langle\varphi_{\mathrm{LM}}^{\mathrm{ac}}(1)\left|\mathrm{V}_{\mathrm{S}}(12)\right| \varphi_{\mathrm{LM}^{(2)}}^{\mathrm{db}}\right\rangle
\end{aligned}
$$

and

$$
\varphi_{\mathrm{LM}}^{\mathrm{ac}}(1) \equiv \mathrm{u}_{\mathrm{a}}\left(\mathrm{r}_{1}\right) \mathrm{u}_{\mathrm{c}}^{*}\left(\mathrm{r}_{1}\right) \mathrm{Y}_{\mathrm{LM}}\left(\hat{\mathrm{r}}_{1}\right)
$$

In the derivation of equation (14) $\mathrm{V}_{\mathrm{S}}$ is assumed central so that the sums over $\mathrm{L}^{\prime \prime}$ and $M^{\prime \prime}$ reduce to a single ter $m$.

The final step is the inclusion of isotopic spin dependence. It is assumed that

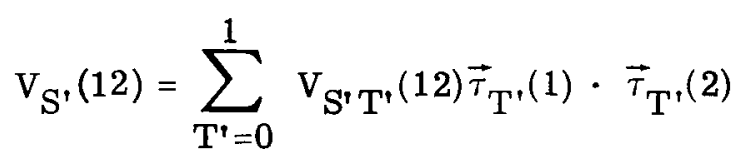

where $\vec{\tau}_{0}$ and $\vec{\tau}_{1}$ are defined like $\vec{\sigma}_{0}$ and $\vec{\sigma}_{1}$ but in isotopic spin space. The treatment is evidently exactly like that given for the spin dependence. With the customary assumption that 


$$
\mathrm{V}_{\mathrm{S}^{\prime} \mathrm{T}^{\prime}}(12)=\beta_{\mathrm{S}^{\prime} \mathrm{T}^{\prime}} \mathrm{V}\left(\left|\overrightarrow{\mathrm{r}}_{1}-\overrightarrow{\mathrm{r}}_{2}\right|\right)
$$

where $\beta_{S^{\prime} T^{\prime}}$ measures the relative strengths of $\mathrm{V}_{\mathrm{S}^{\prime} \mathrm{T}^{\prime}}$, the final result is obtained:

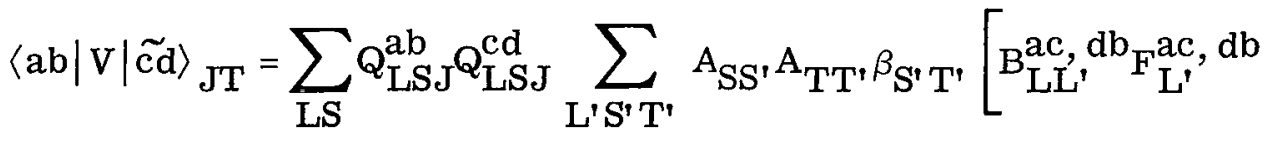

$$
\begin{aligned}
& \left.-(-1)^{\mathrm{L}+\mathrm{S}+\mathrm{T}+l} \mathrm{c}^{+l} \mathrm{~d}_{\mathrm{B}_{\mathrm{L}^{\prime}}^{\mathrm{ad}}, \mathrm{cb}} \mathrm{F}_{\mathrm{L}^{\prime}}^{\mathrm{ad}, \mathrm{cb}}\right]
\end{aligned}
$$

where

$$
F_{L}^{a c, d b}=\left\langle\varphi_{L M^{(1)}}^{a c}|V| \varphi_{L M}^{d b}(2)\right\rangle
$$

The method used to evaluate integral (21) is based on a technique due to Sawaguri and Tobocman (ref. 4), who developed a general formalism for evaluation of sixdimensional integrals. A simplified version adequate for the work herein is obtained as follows. Let

$$
f_{l \mathrm{mn}}(\overrightarrow{\mathrm{r}}) \equiv \mathscr{F}_{\mathrm{n}}^{l}(\mathrm{r}) \mathrm{Y}_{\ell \mathrm{m}}(\hat{\mathrm{r}})
$$

be a complete set of functions in terms of which the expansion

$$
\mathrm{V}\left(\left|\overrightarrow{\mathrm{r}}-\overrightarrow{\mathrm{r}}_{2}\right|\right)=\sum_{\substack{l \mathrm{~m} \\ \mathrm{n}_{1} \mathrm{n}_{2}}} \mathrm{~V}_{\mathrm{n}_{1} \mathrm{n}_{2} l} f_{l \mathrm{mn}_{1}}\left(\overrightarrow{\mathrm{r}}_{1}\right) f_{l \mathrm{mn}_{2}}^{*}\left(\overrightarrow{\mathrm{r}}_{2}\right)
$$

is made. The desired integral (21) may then be written

$$
F_{L}^{a c, d b}=\sum_{n_{1} n_{2}}^{\infty} v_{n_{1} n_{2} L} F_{n_{1} L_{1}}^{a c}\left(F_{n_{2} L}^{d b}\right)^{*}
$$

where 


$$
\mathrm{F}_{\mathrm{nL}}^{\mathrm{ac}}=\int_{0}^{\infty} \mathrm{u}_{\mathrm{a}}^{*}(\mathrm{r}) \mathscr{F}_{\mathrm{n}}^{\mathrm{L}}(\mathrm{r}) \mathrm{u}_{\mathrm{c}}(\mathrm{r}) \mathrm{r}^{2} \mathrm{dr}
$$

The usefulness of the method depends on whether the series in equation (24) is rapidly convergent and whether values of $\mathrm{V}_{\mathrm{n}_{1} \mathrm{n}_{2} l}$ are easy to obtain. Sawaguri and Tobocman showed that for the choice

$$
\mathscr{F}_{\mathrm{n}}^{l}(\mathrm{r})=\mathscr{F}_{\mathrm{n}}^{l}(\alpha, \beta \mathrm{r}) \equiv \frac{1}{\mathrm{n} !}(\beta \mathrm{r})^{l} \mathrm{e}^{-\alpha^{2} \beta^{2} \mathrm{r}^{2} / 2}{ }_{1} \mathrm{~F}_{1}\left(-\mathrm{n} ; l+3 / 2 ; \beta^{2} \mathrm{r}^{2}\right)
$$

one gets

$$
\mathrm{v}_{\mathrm{n}_{1} \mathrm{n}_{2} l}=\sum_{\mathrm{m}_{1}=0}^{\mathrm{n}_{1}} \sum_{\mathrm{m}_{2}=0}^{\mathrm{n}_{2}} \mathrm{G}_{\mathrm{m}_{1} \mathrm{n}_{1}}^{\mathrm{G}} \mathrm{G}_{\mathrm{m}_{2} \mathrm{n}_{2}}^{\mathrm{n}} \mathrm{v}_{\mathrm{m}_{1}+\mathrm{m}_{2}+l}
$$

where

$$
\mathrm{V}_{\mathrm{m}}=\pi\left(\frac{2 \beta}{\sqrt{2-\alpha}}\right)^{3} \frac{\Gamma\left(\mathrm{m}+\frac{3}{2}\right)}{(-\alpha)^{\mathrm{m}}} \int_{0}^{\infty} \mathrm{V}(\mathrm{r}) \mathscr{F}_{\mathrm{m}}^{0}\left(2, \frac{\sqrt{2-\alpha}}{2} \beta \mathrm{r}\right) \mathrm{r}^{2} \mathrm{dr}
$$

and

$$
\mathrm{G}_{\mathrm{mn}}^{l}=\left(\frac{-\alpha}{2-\alpha}\right)^{\mathrm{n}+l / 2}\left(\begin{array}{c}
\mathrm{n} \\
\mathrm{m}
\end{array}\right) \frac{\Gamma\left(\mathrm{n}+\imath+\frac{3}{2}\right)}{\Gamma\left(l+\frac{3}{2}\right) \Gamma\left(\mathrm{m}+l+\frac{3}{2}\right)}
$$

In practice, for appropriate choices of $\alpha$ and $\beta$, the series in equation (24) can be made to converge sufficiently fast to make the entire scheme an excellent computational device.

\section{RESULTS}

The theory just described has been applied to the five s-d shell nuclei neon 20, magnesium 24 , silicon 28 , sulfur 32 , and argon $36\left(\mathrm{Ne}^{20}, \mathrm{Mg}^{24}, \mathrm{Si}^{28}, \mathrm{~s}^{32}\right.$, and $\left.\mathrm{A}^{36}\right)$. The HF wave functions are assumed to have axial symmetry (ref. 5), and they are formed by 
putting particles into deformed orbits about a spherical, closed-shell, inert oxygen 16 $\left(\mathrm{O}^{16}\right)$ core. Each deformed orbit is described as a mixture of $1 \mathrm{~d}_{5 / 2}, 2 \mathrm{~s}_{1 / 2}$, and $1 \mathrm{~d}_{3 / 2}$ basis vectors, each with the appropriate spin projection $m_{\lambda}$. The coefficients for the negative $\mathrm{m}_{\lambda}$ orbits are related to those for the positive $\mathrm{m}_{\lambda}$ orbits by time reversal symmetry:

$$
C_{j}^{\lambda}\left(-m_{\lambda}\right)=C_{j}^{\lambda}\left(m_{\lambda}\right)(-1)^{j-m_{\lambda}}
$$

The eigenvalues of $h_{0}$ used in the calculation are taken from the experimental spectrum of oxygen $17\left(\mathrm{O}^{17}\right)$, and they are listed in the fourth column of table $\mathrm{I}$. The residual two-body force $V(i j)$ is a Rosenfeld mixture with Gaussian shape, much like that used by Ripka (ref. 1):

$$
\mathrm{V}(\mathrm{ij})=\mathrm{V}_{\mathrm{o}} \frac{\vec{\tau}_{\mathrm{i}} \cdot \vec{\tau}_{\mathrm{j}}}{3}\left[0.3+0.7 \vec{\sigma}_{1}(\mathrm{i}) \cdot \vec{\sigma}_{1}(\mathrm{j})\right] \mathrm{e}^{-\mu r_{\mathrm{ij}}^{2}}
$$

with $\mathrm{V}_{\mathrm{o}}=-50 \mathrm{MeV}$ (instead of Ripka's $\mathrm{V}_{\mathrm{o}}=-55 \mathrm{MeV}$ ) and $\mu=0.29$ per square femtometer $\left(\mathrm{fm}^{-2}\right)$.

For a discussion of the basis vectors themselves, two sets of harmonic oscillator basis functions were used and one set of Wood-Saxon basis functions (ref. 6). The latter were chosen by varying the parameters $\mathrm{V}_{\mathrm{o}}$ and $\alpha$ in the Wood-Saxon potential

$$
\begin{gathered}
\mathrm{V}=\rho(\mathrm{r})-\alpha\left(\frac{\hbar}{2 \mathrm{mc}}\right)^{2} \vec{\sigma} \cdot \vec{\imath} \frac{1}{\mathrm{r}} \frac{\mathrm{d} \rho}{\mathrm{dr}} \\
\rho(\mathrm{r})=\frac{\mathrm{V}_{\mathrm{o}}}{\left[1+\exp \left(\frac{\mathrm{r}-\mathrm{R}}{\mathrm{a}}\right)\right]}
\end{gathered}
$$

so as to reproduce as closely as possible the experimental eigenvalues of $h_{o}$ as given in table I. The eigenvalues thus obtained are given in the third column of table I.

Choosing the harmonic oscillator basis functions poses something of a problem namely, what criteria to use. At length it was decided that one set of functions (HO - 1) should be chosen on the basis of similarity to the Wood-Saxon basis functions within the nuclear interior, as measured by comparison of eigenvalues and location of peaks and nodes in the functions. For this set an optimum choice was $\nu=0.35 \mathrm{fm}^{-2}$. This choice $\nu$ is based on an approximate method for calculating the "correct" nuclear radius (ref. 7). 
TABLE I. - OXYGEN 17 SINGLE-PARTICLE ENERGIES

\begin{tabular}{|c|c|c|c|c|}
\cline { 2 - 3 } & \multicolumn{3}{|c|}{ Energy, MeV } \\
\cline { 2 - 3 } & $\begin{array}{r}\text { Harmonic oscillator parameter, } \\
\nu, \mathrm{fm}^{-2}\end{array}$ & Wood-Saxon & Experiment \\
\cline { 2 - 3 } & $\nu=0.27 \mathrm{fm}^{-2}$ & $\nu=0.35 \mathrm{fm}^{-2}$ & & \\
\hline $1 \mathrm{~s}_{1 / 2}$ & -26.2 & -32.6 & -34.68 & $\sim-35$ \\
$1 \mathrm{p}_{3 / 2}$ & -15.0 & -18.2 & -20.21 & -21.83 \\
$1 \mathrm{p}_{1 / 2}$ & -15.0 & -18.2 & -16.53 & -15.67 \\
$1 \mathrm{~d}_{5 / 2}$ & -3.7 & -3.7 & -6.02 & -4.14 \\
$2 \mathrm{~s}_{1 / 2}$ & -3.7 & -3.7 & -4.54 & -3.27 \\
$1 \mathrm{~d}_{3 / 2}$ & -3.7 & -3.7 & -0.53 & 0.94 \\
\hline
\end{tabular}

A second set (HO - 2) was chosen eventually on the basis of similarity to the WoodSaxon basis functions as measured by comparison of the resulting nuclear binding energies, orbital energies, energy gaps, and intrinsic quadrupole moments. For this set, $\nu=0.27 \mathrm{fm}^{-2}$.

In table I the energy eigenvalues of the various basis functions are compared, while in figures 1 to 5 their shapes are compared. Little can be determined from the energy eigenvalues, but figures 1 to 5 reveal clearly for the 1s-ip shell functions that HO- 1 is closer to WS than HO-2 is. In the $2 \mathrm{~s}-1 \mathrm{~d}$ shell the situation is somewhat ambiguous:

HO - 1 has the same peaks and nodes as WS, as before, whereas HO-2 has different peaks and nodes but has perhaps an overall better match in magnitude.

The results of HF calculations using the three sets of basis functions just described are compared in tables $\Pi(\mathrm{a})$ and (b). On the basis of the binding energies and the gaps, it is evident that HO-2 gives a better match to the WS results than HO- 1 .

\section{Root-Mean-Square Radii}

The $\mathrm{rms}$ radii are obtained from evaluation of the expectation value of the operator

$$
\overrightarrow{\mathrm{R}}^{2}=\sum_{\mathrm{i}=1}^{\mathrm{A}} \overrightarrow{\mathrm{r}}_{\mathrm{i}}^{2}
$$




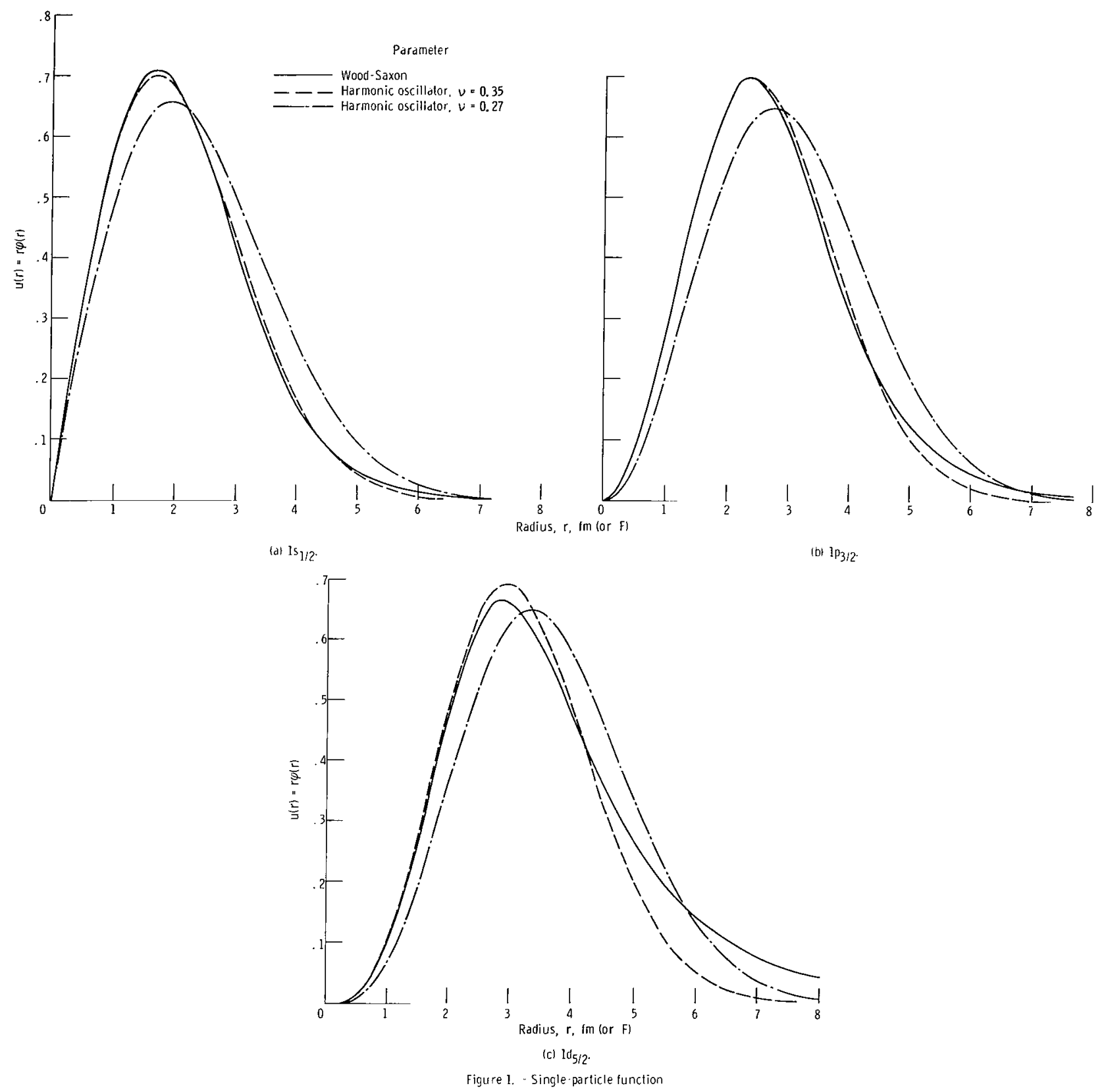




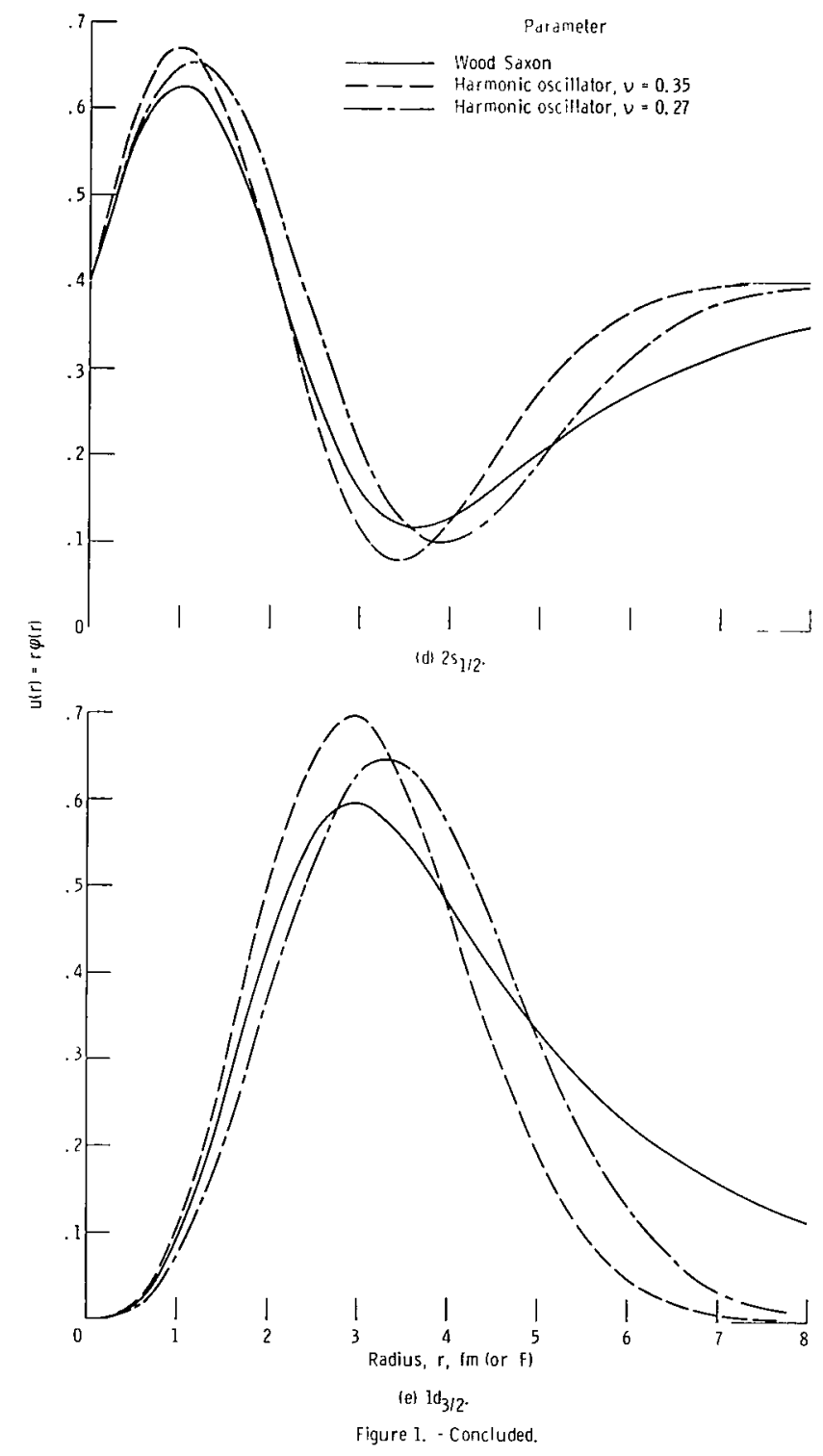




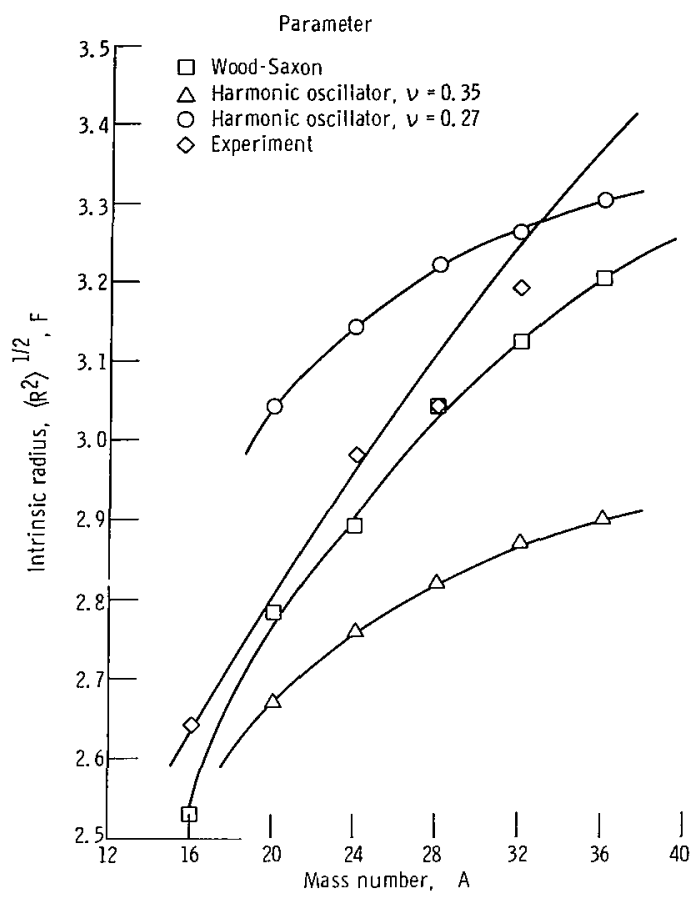
Figure 2. - Intrinsic radius $\left\langle R^{2}\right\rangle^{1 / 2}$ against mass number $A$
for the $4 n 2 s-1 d$ shell nuclei.

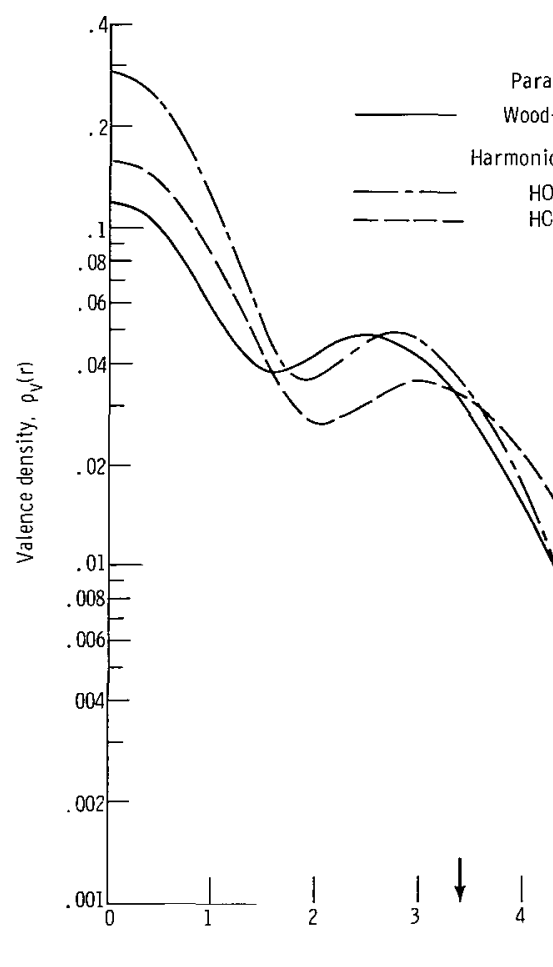

(a) Valence density.
Parameter

Wood-Saxon

rmonic oscillator

$\mathrm{HO}-1$
$\mathrm{HC}-2$ 

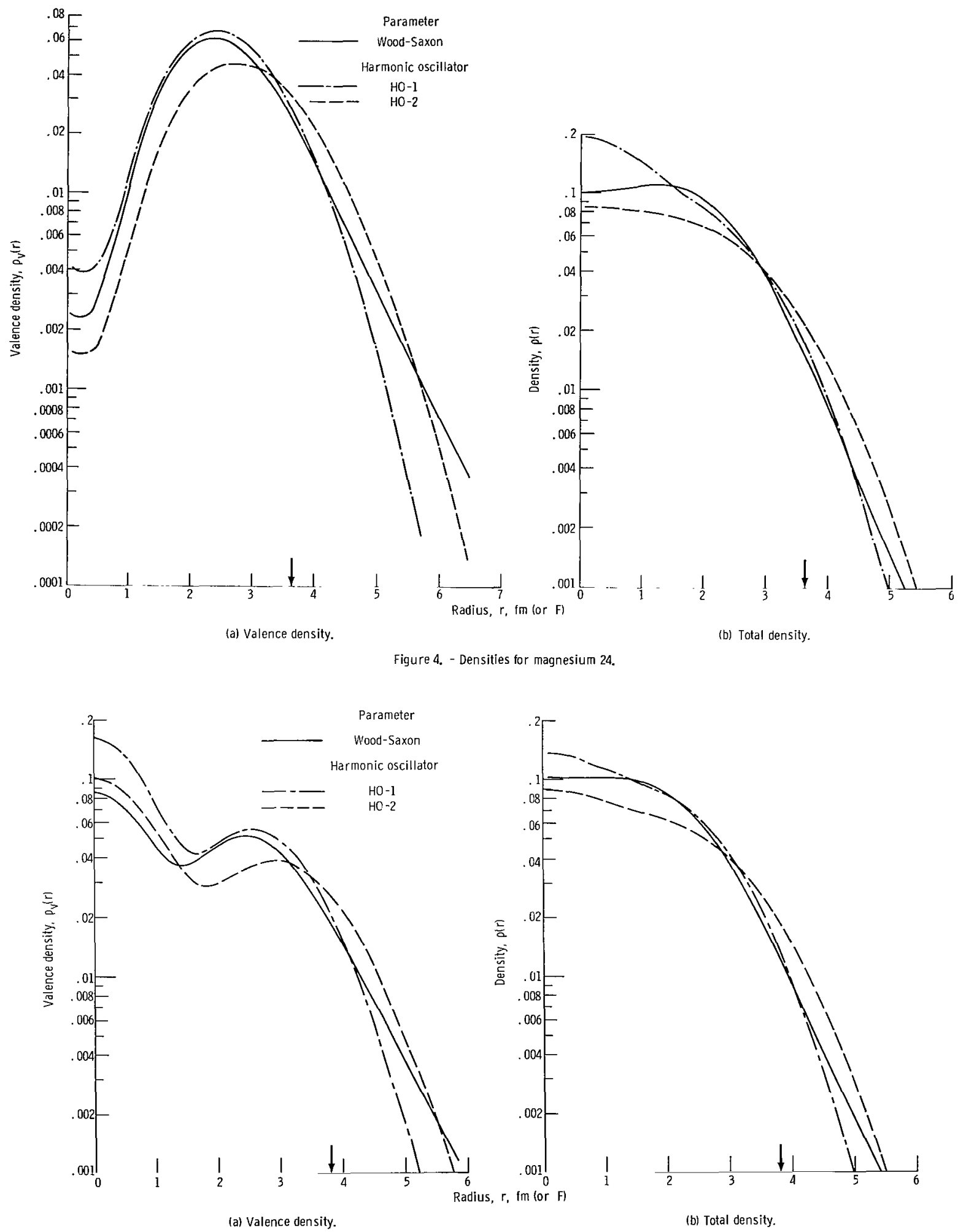

Figure 5. - Densities for silicon 28. 
[Results using a Wood-Saxon basis are in boldface type; light type corresponds to a harmonic oscillator basis with a stated harmonic oscillator parameter $\nu$. ]

(a) Harmonic oscillator parameter, $\nu=0.35 \mathrm{fm}^{-2}$

\begin{tabular}{|c|c|c|c|c|c|c|c|c|c|c|}
\hline \multirow[t]{2}{*}{ Nucleus } & \multirow{2}{*}{$\begin{array}{l}\text { Hartree-Fock } \\
\text { energy. } \\
\mathrm{E}_{\mathrm{HF}}, \\
\mathrm{MeV}\end{array}$} & \multirow{2}{*}{$\begin{array}{c}\text { Energy gap, } \\
\Delta, \\
\mathrm{MeV}\end{array}$} & \multirow{2}{*}{$\begin{array}{l}\text { Single-particle } \\
\text { Hartree-Fock } \\
\text { energy, } \\
\mathrm{e}_{\lambda}, \\
\mathrm{MeV}\end{array}$} & \multirow{2}{*}{$\begin{array}{c}\text { Projection of } \\
\text { angular momentum } \\
\text { on } \mathrm{z} \text {-axis, } \\
\mathrm{m}_{\lambda}\end{array}$} & \multicolumn{6}{|c|}{ Projection of the Hartree-Fock orbits on spherical basis, $C_{j}^{\lambda}$} \\
\hline & & & & & $1 d_{5 / 2,1 / 2}$ & $1 d_{5 / 2,3 / 2}$ & $1 d_{5 / 2,1 / 2}$ & $2 \mathrm{~s}_{1 / 2,1 / 2}$ & $1 \mathrm{~d}_{3 / 2,1 / 2}$ & $1 \mathrm{~d}_{3 / 2,3 / 2}$ \\
\hline $\mathrm{Ne}^{20}$ & $\begin{array}{l}-40.21 \\
-35.27 \\
\end{array}$ & $\begin{array}{r}10.6 \\
8.5 \\
\end{array}$ & $\begin{array}{r}-17.01 \\
-14.46 \\
\end{array}$ & $\begin{array}{l}1 / 2 \\
1 / 2\end{array}$ & $\begin{array}{r}0.6781 \\
.7782 \\
\end{array}$ & & & $\begin{array}{r}-0.6342 \\
-.4943 \\
\end{array}$ & $\begin{array}{r}-0.3715 \\
-.3874 \\
\end{array}$ & \\
\hline \multirow[t]{2}{*}{$\mathrm{Mg}^{24}$} & \multirow[t]{2}{*}{$\begin{array}{l}-72.28 \\
-68.26\end{array}$} & $\begin{array}{l}4.9 \\
5.0 \\
\end{array}$ & $\begin{array}{l}-15.88 \\
-14.78 \\
\end{array}$ & $\begin{array}{l}3 / 2 \\
3 / 2 \\
\end{array}$ & & $\begin{array}{r}0.9559 \\
.9550 \\
\end{array}$ & & & & $\begin{array}{r}-0.2938 \\
-.2835 \\
\end{array}$ \\
\hline & & & $\begin{array}{r}-13.83 \\
-12.78 \\
\end{array}$ & $\begin{array}{l}1 / 2 \\
1 / 2\end{array}$ & $\begin{array}{r}0.8414 \\
.8552 \\
\end{array}$ & & & $\begin{array}{r}-0.1080 \\
-.0997\end{array}$ & $\begin{array}{r}0.5294 \\
.5086 \\
\end{array}$ & \\
\hline \multirow[t]{3}{*}{$\mathrm{Si}^{28}$} & \multirow[t]{3}{*}{$\begin{array}{r}-132.45 \\
-116.80\end{array}$} & $\begin{array}{l}8.2 \\
7.1 \\
\end{array}$ & $\begin{array}{l}-21.93 \\
-18.37 \\
\end{array}$ & $\begin{array}{l}1 / 2 \\
5 / 2\end{array}$ & 0.4798 & & 1.000 & 0.8320 & -0.2787 & \\
\hline & & & $\begin{array}{r}-19.95 \\
-17.16 \\
\end{array}$ & $\begin{array}{l}5 / 2 \\
1 / 2 \\
\end{array}$ & 0.6066 & & 1.000 & 0.7345 & -0.3040 & \\
\hline & & & $\begin{array}{l}-15.86 \\
-13.98 \\
\end{array}$ & $\begin{array}{l}3 / 2 \\
3 / 2 \\
\end{array}$ & & $\begin{array}{r}0.6440 \\
.6959 \\
\end{array}$ & & & & $\begin{array}{r}0.7650 \\
.7182 \\
\end{array}$ \\
\hline \multirow[t]{4}{*}{$\mathrm{s}^{32}$} & \multirow[t]{4}{*}{$\begin{array}{l}-179.64 \\
-157.89\end{array}$} & $\begin{array}{l}5.9 \\
5.0\end{array}$ & $\begin{array}{l}-22.66 \\
-18.35\end{array}$ & $\begin{array}{l}1 / 2 \\
5 / 2\end{array}$ & 0.4083 & & 1.000 & 0.8830 & -0.2315 & \\
\hline & & & $\begin{array}{l}-20.24 \\
-18.11 \\
\end{array}$ & $\begin{array}{l}5 / 2 \\
1 / 2\end{array}$ & 0.8167 & & 1.000 & 0.4404 & -0.3730 & \\
\hline & & & $\begin{array}{r}-18.55 \\
-15.14 \\
\end{array}$ & $\begin{array}{l}1 / 2 \\
1 / 2 \\
\end{array}$ & $\begin{array}{r}0.7965 \\
-.4162 \\
\end{array}$ & & & $\begin{array}{r}-0.4685 \\
.8972 \\
\end{array}$ & $\begin{array}{r}-0.3823 \\
.1481\end{array}$ & \\
\hline & & & $\begin{array}{l}-16.22 \\
-14.35\end{array}$ & $\begin{array}{l}3 / 2 \\
3 / 2\end{array}$ & & $\begin{array}{r}0.7030 \\
.7889 \\
\end{array}$ & & & & $\begin{array}{r}0.7112 \\
.6145 \\
\end{array}$ \\
\hline \multirow[t]{5}{*}{$\mathrm{Ar}^{36}$} & \multirow[t]{5}{*}{$\begin{array}{l}-238.56 \\
-209.66\end{array}$} & $\begin{array}{l}8.1 \\
6.9 \\
\end{array}$ & $\begin{array}{l}-25.07 \\
-21.41 \\
\end{array}$ & $\begin{array}{l}1 / 2 \\
5 / 2\end{array}$ & 0.3607 & & 1.000 & 0.9268 & -0.1040 & \\
\hline & & & $\begin{array}{l}-23.05 \\
-20.38 \\
\end{array}$ & $\begin{array}{l}5 / 2 \\
3 / 2 \\
\end{array}$ & & 0.9968 & 1.000 & & & 0.0801 \\
\hline & & & $\begin{array}{l}-22.27 \\
-19.47 \\
\end{array}$ & $\begin{array}{l}3 / 2 \\
1 / 2\end{array}$ & 0.6691 & 0.9969 & & 0.7419 & 0.0431 & 0.0781 \\
\hline & & & $\begin{array}{l}-18.94 \\
-16.16\end{array}$ & $\begin{array}{l}1 / 2 \\
1 / 2\end{array}$ & $\begin{array}{r}0.7411 \\
.5498 \\
\end{array}$ & & & $\begin{array}{r}-0.2172 \\
-.5332\end{array}$ & $\begin{array}{r}0.6352 \\
.6429 \\
\end{array}$ & \\
\hline & & & $\begin{array}{l}-17.18 \\
-14.57\end{array}$ & $\begin{array}{l}3 / 2 \\
3 / 2\end{array}$ & & $\begin{array}{r}-0.0781 \\
-.0801\end{array}$ & & & & $\begin{array}{r}0.9969 \\
.9968\end{array}$ \\
\hline
\end{tabular}


(b) Harmonic oscillator parameter, $\nu=0.27 \mathrm{fm}^{-2}$

\begin{tabular}{|c|c|c|c|c|c|c|c|c|c|c|}
\hline $\mathrm{Ne}^{20}$ & $\begin{array}{l}-34.82 \\
-35.27 \\
\end{array}$ & $\begin{array}{l}8.2 \\
8.5 \\
\end{array}$ & $\begin{array}{r}-14.27 \\
-14.46 \\
\end{array}$ & $\begin{array}{l}1 / 2 \\
1 / 2 \\
\end{array}$ & $\begin{array}{r}0.7273 \\
.7782 \\
\end{array}$ & & & $\begin{array}{r}-0.5729 \\
-.4943 \\
\end{array}$ & $\begin{array}{r}-0.3780 \\
-.3874 \\
\end{array}$ & \\
\hline \multirow[t]{2}{*}{$\mathrm{Mg}^{24}$} & \multirow[t]{2}{*}{$\begin{array}{l}-65.99 \\
-68.26\end{array}$} & $\begin{array}{l}4.8 \\
5.0 \\
\end{array}$ & $\begin{array}{r}-14.14 \\
-14.78 \\
\end{array}$ & $\begin{array}{l}3 / 2 \\
3 / 2 \\
\end{array}$ & & $\begin{array}{r}0.9562 \\
.9550 \\
\end{array}$ & & & & $\begin{array}{r}-0.2928 \\
-.2835 \\
\end{array}$ \\
\hline & & & $\begin{array}{r}-12.52 \\
-12.78 \\
\end{array}$ & $\begin{array}{l}1 / 2 \\
1 / 2\end{array}$ & $\begin{array}{r}0.8333 \\
.8552 \\
\end{array}$ & & & $\begin{array}{r}-0.0809 \\
-.0997\end{array}$ & $\begin{array}{r}0.5469 \\
.5086 \\
\end{array}$ & \\
\hline \multirow[t]{3}{*}{$\mathrm{Si}^{28}$} & \multirow[t]{3}{*}{$\begin{array}{l}-116.41 \\
-116.80\end{array}$} & $\begin{array}{l}7.0 \\
7.1 \\
\end{array}$ & $\begin{array}{r}-17.94 \\
-18.37 \\
\end{array}$ & $\begin{array}{l}1 / 2 \\
5 / 2 \\
\end{array}$ & 0.5290 & & 1.000 & 0.7967 & -0.2922 & \\
\hline & & & $\begin{array}{r}-17.55 \\
-17.16 \\
\end{array}$ & $\begin{array}{l}5 / 2 \\
1 / 2 \\
\end{array}$ & 0.6066 & & 1.000 & 0.7345 & -0.3040 & \\
\hline & & & $\begin{array}{l}-14.07 \\
-13.98 \\
\end{array}$ & $\begin{array}{l}3 / 2 \\
3 / 2 \\
\end{array}$ & & $\begin{array}{r}0.6682 \\
.6959 \\
\end{array}$ & & & & $\begin{array}{r}0.7440 \\
.7182 \\
\end{array}$ \\
\hline \multirow[t]{4}{*}{$\mathrm{s}^{32}$} & \multirow[t]{4}{*}{$\begin{array}{l}-159.06 \\
-157.89\end{array}$} & $\begin{array}{l}5.0 \\
5.0 \\
\end{array}$ & $\begin{array}{l}-18.76 \\
-18.35 \\
\end{array}$ & $\begin{array}{l}1 / 2 \\
5 / 2 \\
\end{array}$ & 0.5757 & & 1.000 & 0.7598 & -0.3020 & \\
\hline & & & $\begin{array}{r}-17.76 \\
-18.11 \\
\end{array}$ & $\begin{array}{l}5 / 2 \\
1 / 2 \\
\end{array}$ & 0.8167 & & 1.000 & 0.4404 & -0.3730 & \\
\hline & & & $\begin{array}{l}-16.11 \\
-15.14 \\
\end{array}$ & $\begin{array}{l}1 / 2 \\
1 / 2 \\
\end{array}$ & $\begin{array}{r}0.6928 \\
-.4162 \\
\end{array}$ & & & $\begin{array}{r}-0.6495 \\
.8972 \\
\end{array}$ & $\begin{array}{r}-0.3133 \\
.1481 \\
\end{array}$ & \\
\hline & & & $\begin{array}{l}-14.48 \\
-14.35 \\
\end{array}$ & $\begin{array}{l}3 / 2 \\
3 / 2 \\
\end{array}$ & & $\begin{array}{r}0.7333 \\
.7889 \\
\end{array}$ & & & & $\begin{array}{r}0.6799 \\
.6145 \\
\end{array}$ \\
\hline \multirow[t]{5}{*}{$\mathrm{Ar}^{36}$} & \multirow[t]{5}{*}{$\begin{array}{l}-211.89 \\
-209.66\end{array}$} & $\begin{array}{l}7.1 \\
6.9\end{array}$ & $\begin{array}{l}-20.68 \\
-21.41 \\
\end{array}$ & $\begin{array}{l}5 / 2 \\
5 / 2 \\
\end{array}$ & & & $\begin{array}{l}1.000 \\
1.000 \\
\end{array}$ & & & \\
\hline & & & $\begin{array}{l}-20.40 \\
-20.38 \\
\end{array}$ & $\begin{array}{l}1 / 2 \\
3 / 2 \\
\end{array}$ & 0.4868 & 0.9968 & & 0.8716 & -0.0576 & 0.0801 \\
\hline & & & $\begin{array}{l}-19.81 \\
-19.47 \\
\end{array}$ & $\begin{array}{l}3 / 2 \\
1 / 2 \\
\end{array}$ & 0.6691 & 0.9960 & & 0.7419 & 0.0431 & 0.0895 \\
\hline & & & $\begin{array}{r}-16.87 \\
-16.16 \\
\end{array}$ & $\begin{array}{l}1 / 2 \\
1 / 2 \\
\end{array}$ & $\begin{array}{r}0.6828 \\
.5498 \\
\end{array}$ & & & $\begin{array}{r}-0.3386 \\
-.5332\end{array}$ & $\begin{array}{r}0.6475 \\
.6429 \\
\end{array}$ & \\
\hline & & & $\begin{array}{l}-15.42 \\
-14.57\end{array}$ & $\begin{array}{l}3 / 2 \\
3 / 2\end{array}$ & & $\begin{array}{r}-0.0895 \\
-.0801\end{array}$ & & & & $\begin{array}{r}0.9960 \\
.9968\end{array}$ \\
\hline
\end{tabular}


between HF states $\Phi$. The results, shown in figure 2, differ considerably for the three sets of basis functions, and only the WS results bear a reasonable resemblance to experiment and then only in an average sense. As the mass number increases toward 40 , the WS results begin to deviate even more from experiment. The HO results are quite poor in both cases. However, the comparison of all these results with experiment would be much more meaningful if the expectation values were taken with respect to states of good angular momentum. The results are, nonetheless, significant for nuclear matter studies.

\section{Intrinsic Quadrupole Moment}

The intrinsic quadrupole moment is defined as the expectation value of the operator

$$
\mathrm{Q}_{\mathrm{o}}=\mathrm{e}\left(\frac{16 \pi}{5}\right)^{1 / 2} \sum_{\mathrm{i}=1}^{\mathrm{A}}\left[\frac{1+\tau_{3}(\mathrm{i})}{2}\right] \mathrm{r}_{i}^{2} \mathrm{Y}_{2}^{\mathrm{O}}\left(\Omega_{\overrightarrow{r_{i}}}\right)
$$

with respect to $H F$ states $\Phi$. The operator $\tau_{3}$ is an isospin operator with eigenvalues +1 and -1 for protons and neutrons, respectively; e is the proton charge. In table III the results are given for the intrinsic quadrupole moments. The set HO-2 yields a much better match to the WS than does HO-1. The sign of $\left\langle Q_{0}\right\rangle$ for any particular nucleus does not depend on the choice of basis, and the signs are in agreement with the accepted type of deformation (i.e., prolate or oblate) for these nuclei.

TABLE III. - INTRINSIC QUADRUPOLE MOMENT

\begin{tabular}{|c|c|c|c|}
\hline \multirow{2}{*}{ Nucleus } & \multicolumn{3}{|c|}{$\begin{array}{c}\text { Quadrupole moment, } \\
\left\langle\mathrm{Q}_{\mathrm{O}}\right\rangle, \mathrm{e} \mathrm{fm}^{2}\end{array}$} \\
\cline { 2 - 4 } & $\begin{array}{r}\text { Harmonic oscillator parameter, } \\
\nu, \mathrm{fm}^{-2}\end{array}$ & Wood-Saxon \\
\cline { 2 - 4 } & $\nu=0.27 \mathrm{fm}^{-2}$ & $\nu=0.35 \mathrm{fm}^{-2}$ & \\
\hline $\mathrm{Ne}^{20}$ & 29.00 & 22.30 & 29.24 \\
$\mathrm{Mg}^{24}$ & 15.80 & 12.60 & 14.90 \\
$\mathrm{Si}^{28}$ & -42.59 & -33.18 & -42.51 \\
$\mathrm{~S}^{32}$ & -12.74 & -10.25 & -11.74 \\
$\mathrm{~A}^{36}$ & -25.92 & -19.17 & -29.65 \\
\hline
\end{tabular}




\section{Nuclear Density}

The nuclear density function is defined as the expectation value of

$$
\rho=\sum_{i=1}^{\mathrm{A}} \delta\left(\overrightarrow{\mathrm{r}}-\overrightarrow{\mathrm{r}}_{\mathbf{i}}\right)
$$

Since the HF calculations of the type presented here test only the extra-core wave functions, two types of density functions are shown for each of the nuclei. The valence density $\rho_{\mathrm{V}}$ is the expectation value of $\rho$ with respect to wave functions which do not specifically include the spherical core functions. The total density $\rho(r)$ does contain the core effects. In figures 3 to 7 the density functions are presented. In each of the figures, parts (a) and (b) refer to valence and total density, respectively. The arrows which appear on each of the figures indicate the position of $1.25 \mathrm{~A}^{1 / 3}$, where $\mathrm{A}$ is the mass number. Examination of figures 3 to 7 reveals that both sets of density functions (with the exception of $\mathrm{Mg}^{24}$ ) show consistent behavior as one goes from $\mathrm{Ne}^{20}$ to $\mathrm{A}^{36}$. For the moment the problem of $\mathrm{Mg}^{24}$ is set aside, and the general trends for the valence and total densities for the other nuclei are considered.

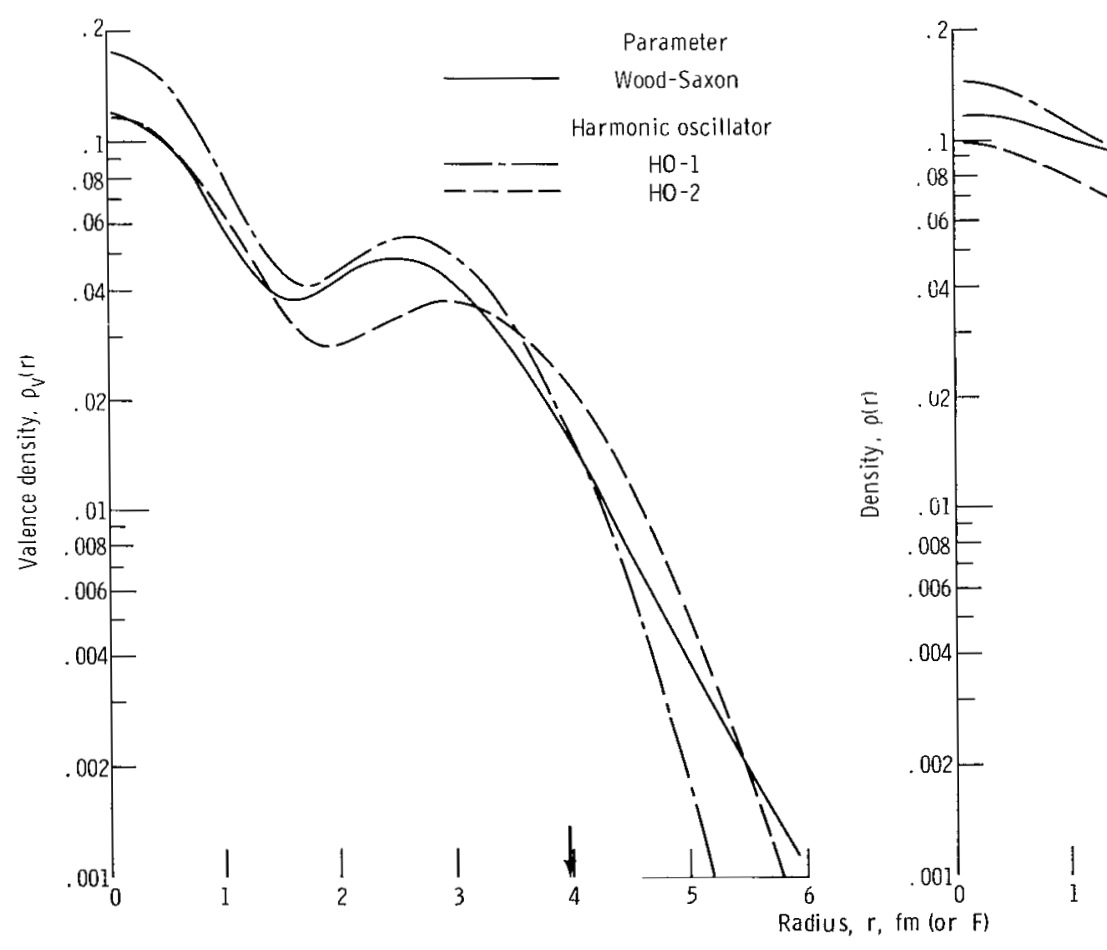

(a) Valence density.

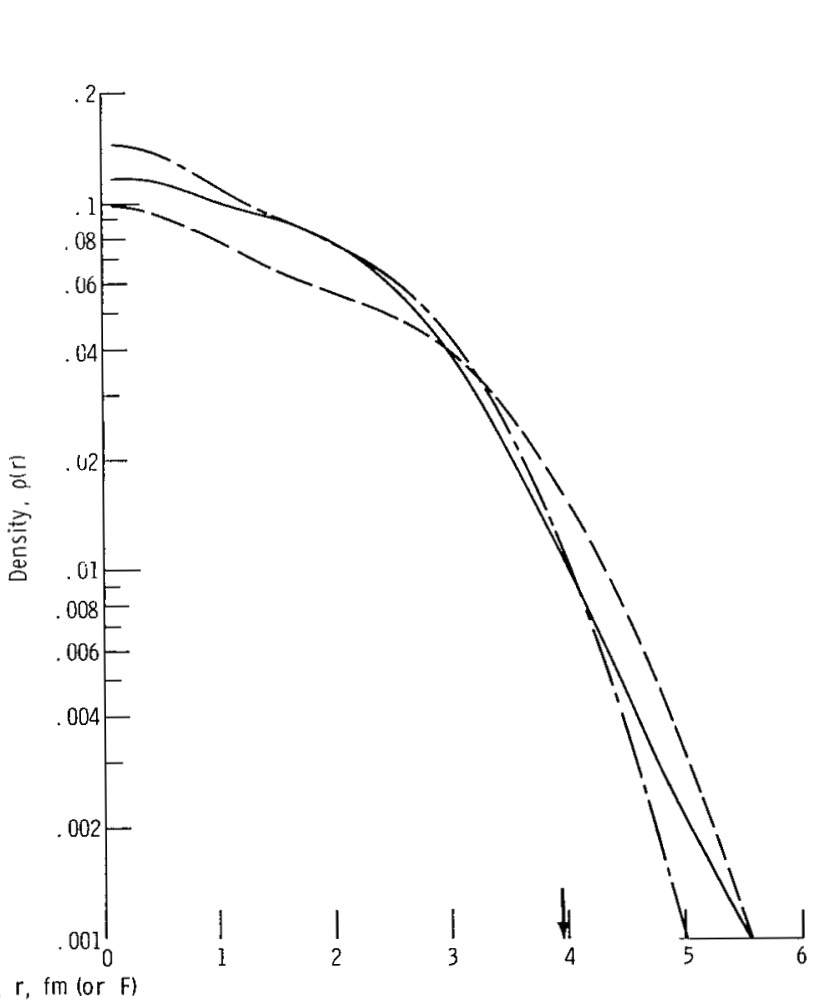

(b) Total density.

Figure 6. - Densities for sulfur 32. 
Valence densities. - It is seen from figures 3(a), 5(a), 6(a), and 7(a) that for $0 \leq \overline{\mathrm{r} \leq 1.5 \text { the HO-2 }}\left(\nu=0.27 \mathrm{fm}^{-2}\right)$ results show better agreement with the WS case than does the HO-1 $\left(\nu=0.35 \mathrm{fm}^{-2}\right)$ result. However, for $1.5 \leq \mathrm{r} \leq 4.2$, HO- 1 agrees more closely with WS. In the region beyond about $4.2 \mathrm{fm}$, the HO-1 densities fall off more rapidly than both the WS and HO-2 densities. The three curves focus at about $3.3 \mathrm{fm}$ for all four nuclei.

Total densities. - The total densities are presented in figures $3(\mathrm{~b}), 5(\mathrm{~b}), 6(\mathrm{~b})$, and 7 (b). For the WS case the flattening near the nuclear center is washed out as $A$ in increases, and all of these total density functions have the same general shape. In the region $1.5 \leq \mathrm{r} \leq 4.3$, the HO- $1\left(\nu=0.35 \mathrm{fm}^{-2}\right)$ results match the WS results quite well, but drop off rapidly beyond $r \approx 4.5$. Beyond $r=5 \mathrm{fm}$ it is observed that the HO-2 $\left(\nu=0.27 \mathrm{fm}^{2}\right)$ results agree more closely with WS as might be expected since this is the same region in which the HO-2 wave functions agree most closely with those of the WS potential.

For the case of $\mathrm{Mg}^{24}$, an examination of figure 4(a) perhaps gives an indication as to why $\mathrm{Mg}^{24}$ should be treated separately. Certainly the valence density has a peculiar appearance in view of the consistent behavior of the other densities. However, Bar-Touv and Kelson (ref. 8) performed calculations which indicate that $\mathrm{Mg}^{24}$ is not axially sym-

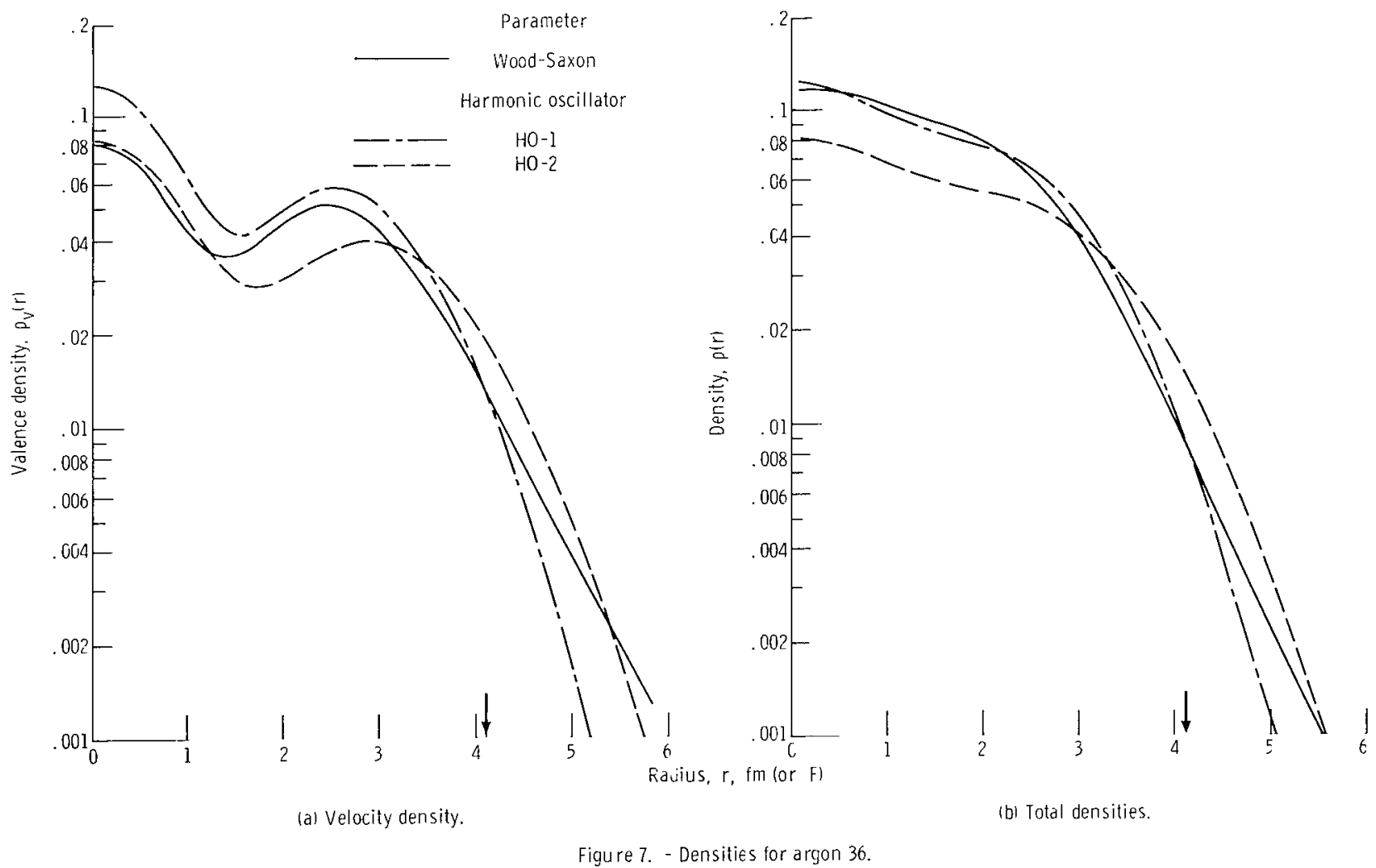


metric, so $\mathrm{Mg}^{24}$ might be expected to have properties which differ from those of axially symmetric nuclei. Based on the findings of Bar-Touv and Kelson, $\mathrm{s}^{32}$ would also be expected to behave similarly, since the same set of calculations indicated that $\mathrm{S}^{32}$ is likewise asymmetric. The size of the gaps in the HF spectra (see tables $\Pi(\mathrm{a})$ and (b)) indicate that the assumption of axial symmetry is equally poor for $\mathrm{s}^{32}$ and $\mathrm{Mg}^{24}$. That is, since the energy gap between occupied and unoccupied orbits is quite a bit smaller for these nuclei than for the others, a perturbation theory calculation would yield larger effects of axial asymmetry for these nuclei than for the others.

In addition, one of the results of attempting to treat $\mathrm{Mg}^{24}$ as axially symmetric is that the coefficient of the $2 \mathrm{~s}_{1 / 2}$ basis vector turns out to be abnormally small, $\sim 0.10$. Consequently, the valence density is drastically reduced at the origin. This does not occur for $\mathrm{s}^{32}$, nor does it occur in an asymmetric treatment (ref. 8) of $\mathrm{Mg}^{24}$.

If asymmetry is assumed, calculations of the energy spectra and other properties of these nuclei, should be more informative than the results just given. However, the previous results do substantiate the belief that $\mathrm{Mg}^{24}$ has to be treated differently than the other $2 \mathrm{~s}-1 \mathrm{~d}$ shell nuclei.

\section{SUMMARY OF RESULTS}

The intrinsic energy spectra, radii, and quadrupole moments have been studied for the five even-even nuclei in the $2 \mathrm{~s}-1 \mathrm{~d}$ shell. The nuclear wave functions were obtained using the HF method. The HF calculations were made using the Wood-Saxon basis functions as well as the more conventional harmonic oscillator basis. It was found that the asymptotic behavior or the WS basis functions could be simulated with harmonic oscillator functions if the oscillator constant were properly chosen. Such oscillator functions were also found to yield the best match to the Woods-Saxon HF spectra, indicating an important dependence on the asymptotic part of the wave function. As expected, $\mathrm{Mg}^{24}$ (and to a lesser extent $\mathrm{S}^{32}$ ) was found to have rather peculiar properties when assumed to be axially symmetric.

Lewis Research Center,

National Aeronautics and Space Administration, Cleveland, Ohio, November 25, 1968, 129-02-07-07-22. 


\section{REFERENCES}

1. Ripka, G.: Hartree-Fock Theory and Nuclear Deformations. Lectures in Theoretical Physics. Vol. VIIIc. University of Colorado Press, 1965, pp. 237-298. Also, see Bouten, M.; Van Leuven, P.; and Depuydt, H.: A Projected Hartree-Fock Calculation for ${ }^{12} \mathrm{C}$. Nucl. Phys., vol. A94, 1967, pp. 687-697.

2. Moshinsky, Marcos: Transformation Brackets for Harmonic Oscillator Functions. Nucl. Phys., vol. 13, 1959, pp. 104-116.

3. Brink, D. M.; and Satchler, G. R.: Angular Momentum. Clarendon Press, Oxford, 1962.

4. Sawaguri, T.; and Tobocman, W.: Finite-Range Effects in Distorted-Wave BornApproximation Calculations of Nucleon Transfer Reactions. J. Math. Phys., vol. 8, no. 11, Nov. 1967, pp. 2223-2230.

5. Gunye, M. R.; and Warke, Chindhu, S.: Projected Hartree-Fock Spectra of 2s-1dShell Nuclei. Phys. Rev., vol. 156, no. 4, Apr. 20, 1967, pp. 1087-1093.

6. Caswell, Randall S. : Improved Fortran Program for Single Particle Energy Levels and Wave Functions in Nuclear Structure Calculations. Tech. Note 410, National Bureau of Standards, Sept. 30, 1966.

7. Moszkowski, S. A.: Models of Nuclear Structure. Handbuch der Physik, Vol. 39. S. Flugge, ed., Springer-Verlag, Berlin, 1957, pp. 411-549.

8. Bar-Touv, J.; and Kelson, I. : Axially Asymmetric Regions in the s-d Shell. Phys. Rev., vol. 138, no. 5B, June 7, 1965, pp. 1035-1041.

9. Jahn, H. A.: Theoretical Studies in Nuclear Structure. II. Nuclear $d^{2}, d^{3}$ and $d^{4}$ Configurations. Fractional Parentage Coefficients and Central Force Matrix Elements. Proc. Roy. Soc., Ser. A, vol. 205, no. 1081, Feb. 7, 1951, pp. 192237. 


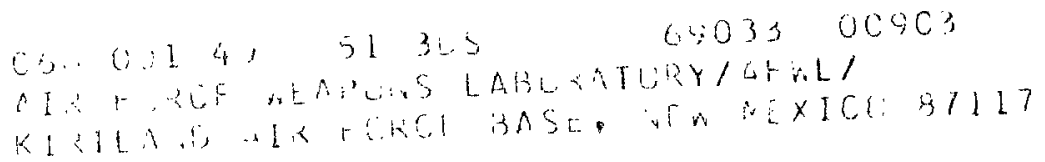

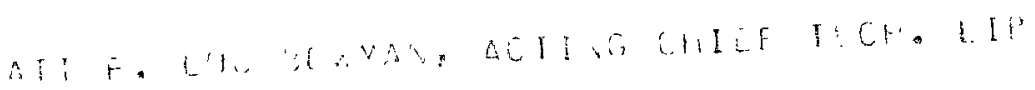

"The aeronatical and space activities of the United States shall be conducted so as to contribute. . . to the expansion of buman knowledge of phenomena in the atmosphere and space. The Administration shall provide for the widest practicable and appropriate dissemination of information concerning its activities and the results thereof."

\section{- National Aeronautics and Space ACt of 1958}

\section{NASA SCIENTIFIC AND TECHNICAL PUBLICATIONS}

TECHNICAL REPORTS: Scientific and technical information considered important, complete, and a lasting contribution to existing knowledge.

TECHNICAL NO'TES: Information less broad in scope but nevertheless of importance as a contribution to existing knowledge.

TECHNICAL MEMORANDUMS:

Information receiving limited distribution becautise of preliminary data, security classification, or other reasons.

CONTRACTOR REPORTS: Scientific and technical information generated under a NASA contract or grant and considered an important contribution to existing knowledge.
TECHNICAL TRANSLATIONS: Information published in a foreign language considered to merit NASA distribution in English.

SPECIAL PUBLICATIONS: Information derived from or of value to NASA activities. Publications include conference proceedings, monographs, data compilations, handbooks, sourcebooks, and special bibliographies.

TECHNOLOGY UTILIZATION PUBLICATIONS: Information on technology used by NASA that may be of particular interest in commercial and other non-aerospace applications. Publications include Tech Briefs, Technology Utilization Reports and Notes, and Technology Surveys.

Details on the availability of these publications may be obtained from:

\section{SCIENTIFIC AND TECHNICAL INFORMATION DIVISION}

